\title{
FROM DUSK OF THE INFORMATION ERA TO DAWN OF THE EXPERIENCE ERA: VIDEOGAMES AS A LEARNING TOOL
}

\author{
Emiliano Chirchiano \\ PhD Fellow, Università degli studi di Napoli Federico II, ITALY, emiliano.chirchiano@unina.it
}

\begin{abstract}
Knowledge institutions are often distracted by themselves and unable to understand what happens in the world of cultural consumption. the videogame, for example, is quite different from all other media forms, owning its peculiar language, the gameplay: an interactive, experiential participation which guarantees a form of involvement that no other medium has. If every medium carries an educational potential, the use of video-games as a learning tool still remains largely undefined. To implement video game within the educational system may look like a radical revolution. We should try different solutions: the so called "gamification" approach, using videogame dynamics within our common educational framework or "Simulation Based Learning" using virtual worlds in which teachers and students can simulate experiences by their own rules. Experience based Learning provided by video games may become the ultimate form of contextual education. It is able to simulate a real-life experience, improving both student engagement and learning. We have to look at the games as a tool, whose value in education depends on how they are used as part a comprehensive strategy. The traditional methods of education are focused on the acquisition of skills in the individual subjects, often neglecting crucial components for success, such as communication and collaboration. I try to define an optimal, real-life solution that decreases the centrality of the written medium, currently at the base of the educational system, merging and integrating it with new tools and techniques, adding to the traditional literacy processes a renewed techno-literacy, necessary for students to communicate and learn.
\end{abstract}

Keywords: Innovation, education, videogames studies, experience learning

\section{CHANGING EDUCATION ONE EXPERIENCE AT A TIME}

In recent years, digital networks, backbone of the medial system, has become fundamental in our daily life, occupying the space of any communicative, creative and cognitive dynamic. The media, unified in the digital language, reached a pervasive extension, mixing people and institutions, transcending any kind of social classification. Each media object, revitalized by this interconnection, shuns the terms of any activity whether professional, formal, academic it is - which, at first, may have supported his growth.

At the base of all social relations of younger generations - those, for instance, raised in an era where digital 
media are integral part of cultural structure - there is a range, large and growing, of non-institutionalized practices that complement, or even replace, those belonging to the sphere of learning and communication. As claimed by Michel De Certeau (1984) although the institutions plan strategies, individuals - during their everyday living - create special tactics to avoid the expected outcome. These spontaneous disruptions of predetermined balance, in the end, become habits that are somehow absorbed and legitimized by institutions.

There are other players in the media system that, just because they born with a strong attitude to entertainment, are still unjustifiably kept from a distance. In spite of enormous commercial success which sees the video-game industry now exceed, in terms of turnover, even the movie business, video games still are seen with scepticism from the world of culture. Looking back, though, we can see how this attitude is not new at all. The institutional knowledge is often distracted by itself and unable to understand what happens in the world of cultural consumption. Comics, television - but also cinema - were kept outside, in our recent past, the educational sphere. Their lack of maturity could try to explain, then, the stigma that they had to share. Nevertheless, the videogame continues, in some ways, to be a medium "removed" (in a Freudian way), becoming victim of an aggressively negative prejudice.

The video game is a complex phenomenon that undermines media system balance existing before its appearance. Even in the term that identifies it: "Video-game", we already find a short-circuit between "different kinds of ancient and modern forms of expression: primitives' performance (homo ludens) and video-sphere (homo videns) of mass industrial society. " (Abruzzese, 1999). As suggested by James Paul Gee (2003), the video game is quite different from all other media forms (film, literature, theatre), despite it retains the same languages. Like film-editing for movies, the peculiar language of the game is the gameplay itself; the interactive, experiential participation which guarantees a form of involvement that no other medium has. If, as we already saw, each of the media system components carries an educational potential, the use of video-games as a learning tool still remains largely undefined and unexplored.

\subsection{Experiential learning and videogames as an educational tool}

In the debate on how technology can transform public education and solve the problems that increasingly afflict it, many hopes are pinned on unorthodox approaches. To use the video game within the educational system may look like a radical revolution. As we will see, there are commercial games that can be used for educational purposes, or games explicitly made for teaching. But you can also try different approaches that mix-up traditional teaching and gaming dynamics. In some cases, you can proceed by subtraction: removing the video from the video-game, inheriting only the ludic dynamics that characterize it, with the so called "gamification" approach. Or, following in reverse order, by subtracting the game from the video: that means removing the rules, the aims and the goals, leaving a virtual world in which teachers and students can simulate experiences by their own rules. This is the case of the "Simulation Based Learning".

For gamification, I mean the use of gaming's typical elements - such as assigning points, the competition with other players - applied to non-recreational activities. The game theories give us new tools for understanding the media ecosystem, increasingly divided and devoid of clear separation between the roles.

Can digital games create new engagement in the field of education for the younger generation? We have to look at the games as a tool, whose value in education depends on how they are used as part a comprehensive strategy. The traditional methods of education are focused on the acquisition of skills in the individual subjects, often neglecting crucial components for success, such as communication and collaboration. Videogames, increasingly supplemented by social components, offer the possibility to weave the development of traditional skills in a transversal way. James Paul Gee says that video games possess the necessary components for optimal learning - a motivation, clear objectives, easily interpretable results, detailed and straightforward feedback. The video-games allow students to share tactics and experiences, showing natural aptitude to acquire skills through a collaborative approach. Traditionally, the development of soft skills - important personal characteristics in any working environment, such as: flexibility, adaptability, planning ability, aptitude for teamwork and leadership - in the school is relegated only in sports activities.

Gamification approach uses the components that make videogames fun, rewarding and challenging, within an educational context. We are not going to use or create a video-game, but we are going to use videogame dynamics within our common educational framework. As an example, I mention platforms like Duolinguo or ClassDojo, or the newly Apple iOS Developer Academy of Federico II University, where each scholarship cycle, which lasts nine months, is based on an approach defined Challenge Based Learning, where students are led to the acquisition of skills by passing certain milestones.

Simulation Based Learning, on the other hand, is an approach based on a video game that faithfully simulates an object, a process or a situation as a learning exercise. As we said before, a simulator that 
allows you to apply the laws of physics involves and amuses students, radically changing the approach to the subject. This is the case, for example, of "Edmondo" an ambitious experiment of the "Indire" project (the Italian institute that deals with research and innovation for the Italian school), a 3D virtual world, based on OpenSimulation - open-source implementation of Second Life - developed to facilitate an experiential approach from teachers and students. Mediated by avatars, the users of "Edmondo" can build environments and move within them, plan activities, communicate with other users and deepen the subjects, from mathematics to art, from history to science or foreign languages. This project explores the possibilities of "immersive learning", through which it is possible, for example, to learn English in a virtual environment that simulates the experience of an airport check-in or learn the natural sciences exploring the inside of a volcano. Whether it is a virtual or augmented reality or just a simulation, in this view, it makes little difference: the goal is to give students an experience that integrates and overcomes the limitations of the simple passing of information.

Game Based Learning, on the other hand, use products designed for entertainment purposes, without any particular changes, to achieve an educational goal. Minecraft or Civilization, for example, were born as commercial entertainment products, but they are extremely suitable tools for learning and development of skills. Videogame is an amazingly effective tool to simulate complex historical, social, economic, and cultural processes. Some videogames indirectly involve study activities, as is the case of the Assassin's Creed saga which, using an historical approach - through the use of real-life characters and locations - awaken in students a renewed interest in the study of history, in a way completely different than traditional learning modalities, involving them in first person. Experience based Learning provided by video games may become the ultimate form of contextual education. It is able to simulate a real-life experience, improving both student engagement and learning. Instead of telling children that they are learning mathematics because they might one day become engineers and design cars, why not let them learn math to design a virtual car to race? If the difference between right or wrong calculation translates into winning a contest, the students will catch immediately the importance of mathematical skills. Furthermore, the games allow students to quickly learn from their mistakes. Instead of waiting weeks for the outcome of a test at school, they have an immediate opportunity to identify what they did wrong and correct it instantly. Just look at a player of Angry birds - a game based scientifically on laws of physics - that automatically learns to recognize its mistakes, correct them and go forward in the game, seamlessly, into a stream that leads to learning in a way as funny as spontaneous.

\subsection{In conclusion}

Teachers, in their school or academic experience, tend to forget that their role - as well as that of experts on the subject - is also to teach literacy. Obviously, when we talk about literacy, we no longer refer only to reading, writing and arithmetic. We entered an era when the definition of what makes a person literate changes, in a continuous evolution. Once again, we cannot ignore the overlap of technics and Culture defined by Alberto Abruzzese (2000) and then integrate the traditional literacy processes with a technoliteracy, necessary for students to communicate: www, videogames, blogs, social networks, video-logs are languages that continually hybridize; we cannot ignore their importance, especially in the delicate processes that affect the learning sphere. Each content area has certain techno-cultural characteristics necessary for students to be able to fully understand it. The optimal solution would be a compromise that decreases the centrality of the written medium, currently at the base of the educational system, merging and integrating it with new tools and techniques.

\section{REFERENCE LIST}

Abruzzese, A. Introduzione in Ascione, C. (1999). Videogames: elogio del tempo sprecato (Vol. 20). Minimum fax.

Abruzzese, A., \& Borrelli, D. (2000). L'industria culturale: tracce e immagini di un privilegio. Carocci.

Abruzzese, A., \& Mancini, P. (2007). Sociologie della comunicazione. Laterza.

Antinucci, F. (1995). La realtà virtuale come strumento di conoscenza. Ginevra, Convegno Telecom, 10, 1595.

Becker, K. (2007, November). Instructional ethology: reverse engineering for serious design of educational 
games. In Proceedings of the 2007 conference on Future Play (pp. 121-128). ACM.

Bittanti, M. (Ed.). (2002). Per una cultura dei videogames: teorie [e] prassi del videogiocare. Unicopli.

Boyd, D. (2010). Streams of Content, Limited Attention: The Flow of Information through Social Media. Educause Review, 45(5), 26.

De Certeau, M., Baccianini, M., Abruzzese, A., \& Borrelli, D. (2001). L'invenzione del quotidiano. Edizioni Lavoro.

Dickey, M. D. (2005). Engaging by design: How engagement strategies in popular computer and video games can inform instructional design. Educational Technology Research and Development, 53(2), 67-83.

Fabricatore, C. (2000). Learning and videogames: An unexploited synergy.

Gee, J. P. (2003). What video games have to teach us about learning and literacy. Computers in Entertainment (CIE), 1(1), 20-20.

Malone, T. W., \& Lepper, M. R. (1987). Making learning fun: A taxonomy of intrinsic motivations for learning. Aptitude, learning, and instruction, 3(1987), 223-253.

Manovich, L. (2013). Software takes command. London: Bloomsbury Publishing.

Maragliano, R. (1996). Esseri multimediali. Immagini del bambino di fine millennio. Firenze, La Nuova.

McGonigal, J. (2011). Reality is broken. New York: Penguin Press.

McLuhan, M. (2011). Capire i media: gli strumenti del comunicare. II Saggiatore.

Paggiarin, V., (2009). Narrazione, Interattività e Performance Ludica nel videogioco: il caso di "In Memoriam". Università IULM (Milano)

Prensky, M. (2005). Engage me or enrage me. Educase Review, 40(5), 61-64.

Shaffer, D. W., Squire, K., Halverson, R., \& Gee, J. P. (2004). Video games and the future of learning. Retrieved December 12, 2004.

Van Eck, R. (2006). Digital game-based learning: It's not just the digital natives who are restless. EDUCAUSE review, 41(2), 16. 